\title{
Dry Sliding Friction Analysis and Wear Behavior of Carbon Nanotubes / Vinylester Nanocomposites, Using Pin-on-Disc Test
}

\author{
ADRIAN COTET ${ }^{1}$, MARIAN BASTIUREA ${ }^{1}$, GABRIEL ANDREI ${ }^{1 *}$, ALINA CANTARAGIU ${ }^{1}$, ANTON HADAR ${ }^{2,3,4}$ \\ 'Dunarea de J os University of Galap, Faculty of Engineering, 47 Domneasca Str., Galati, 800008, Romania \\ ZUniversity Politehnica of Bucharest, Department of Strength of Materials, 313 Splaiul Independentei, Bucharest, 060042, Romania \\ ${ }^{3}$ Academy of Romanian Scientists, 54 Splaiul Independentei, 050085, Bucharest, Romania \\ ${ }^{4}$ Technical Sciences Academy of Romania, 26 Dacia Blvd., 010413, Bucharest, Romania
}

\begin{abstract}
Dry sliding friction and wear behavior of single-wall (SW) and multi-wall (MW) carbon nanotubes (CNTs)/ vinylester composite have been investigated, under several loads and sliding speeds. Three different contents $(0.1,0.15$ and 0.2 wt. \%) of SWCNT and MWCNTs have been dispersed into the vinylester resin in order to obtain polymer nanocomposites. The present study discusses the coefficient of friction, specific wear rate and friction stability of vinylester composites with different CNTS content, using a pin-on-disc test. The friction and wear experiments were carried out following 3 loads $\times 3$ speeds, as test parameters. The best combination of friction and wear properties was found with the nanocomposite containing 0.2 wt.\%MWCNT.
\end{abstract}

Keywords: carbon nanotubes, vinylester, friction, wear

Polymers are some of the most attractive materials because of their noteworthy advantages of stability, good corrosion resistance, easy processing, high toughness, good fatigue strength, chemical stability, self-lubrication, light weight and low cost. Several benefits are the excellent friction and wear resistance, friction stability associated with a high specific compression and flexural strength. These characteristics satisfy the most severe materials requirements in major industrial fields such as shipbuilding, civil engineering, aerospace, oil and gas, naval and green power generation. In order to improve their mechanical and tribological behavior, additive, fillers and reinforcements can be mixed with polymer resin. Conventionally, additives were used to enhance the mechanical and tribological properties of the polymer resin. With the advance of scientific research, the current trend is towards the use of nano-additives as reinforcement for polymer matrix. The growing interest in nano-additives mainly stems from their large specific surface area which enables them to have a great potential to improve the mechanical and tribological behavior of the polymer composites. For this purpose, carbon based nano-additives with high aspect ratios, multi-wall carbon nanotubes (MWCNT) and single-wall carbon nanotube (SWCNT) exhibit great potential for improving the tribological behavior of vinylester resin due to their exceptional morphological, chemical and mechanical characteristics. A strong interfacial interaction between carbon nanotubes and polymer chains is due to CNTs' high ratio, their large specific surface area which provides a large contact area and prevents the motion of molecular chains [1]. A possible explanation for the decrease in friction and wear is that when the local temperature, in the contact area, exceeds the glass transition temperature $(\mathrm{Tg})$ of polymer resin, due to the high sliding speed, the contact surface of polymer resin begins to melt and emerges plastic deformation, and thus the ability to resist shear deformation is weakened [ 2 , 3].

Experimental researches revealed the quality of the interface polymer-filler could improve not only wear behavior, but also mechanical and magnetic/electrical properties of the polymer composites [4-6].
The shear force developing due to the sliding motion exceeds the weak van der Waals forces occurring at the interface between MWCNT and polymer resin. Following the sliding contact, the debris detached from the specimen surface creates a layer consisting of a mixture of polymer resin and carbon nanotubes which acts as micro-bearings that changes sliding friction into rolling friction between the worn surfaces [7-14]. This suggests that the CNTs existing into the sliding interface act as solid lubricant and reduce the coefficient of friction [15-22]. Other studies discuss different explanations for the improved wear behavior such as: uniform dispersion of carbon nanotubes into resin [23-28], polymer film transfer onto the metal counterface [29-34], self-lubrication behavior of carbon nanotubes [35], rolling effect of carbon nanotubes [36] or the occurrence of the third bodyin sliding contact [37-39]. Researchers have found that carbon nanotubes can act as an effective bridge linking the polymer chains into the matrix $[33,40]$, or as a barrier preventing large-scale fragmentation of the polymer [41], despite the natural tendency of the carbon nanotubes to agglomerate, which is an actual drawback $[42,43]$. The increase in microhardness or crystallinity of composite, due to mechanical properties of carbon nanotubes, may account for the decrease in friction and wear $[1,44]$.

Vinylester resins are stronger than polyester resins and weaker than epoxy resins. However, in the past years, one common issue in all mechanical and tribological studies has been the fact that carbon nanotubes tend to agglomerate frequently and form clusters of CNTs, or to disperse asymmetrically into the polymer resin, which affects negatively the wear behaviour. Hence, it is highly advisable to study the lower friction and wear behavior of vinylester composites with uniform dispersion of carbon nanotubes [45]. The aim of this work is to describe the results and discussion over the influence of carbon nanotubes on coefficient of friction (COF), specific wear rate (Ws) and friction stability of vinylester nanocomposites. 


\begin{tabular}{|c|c|c|c|c|c|c|}
$\begin{array}{c}\text { Carbon } \\
\text { nanotubes }\end{array}$ & Purity & Length & $\begin{array}{c}\text { Outside } \\
\text { diameter } \\
{[\%]}\end{array}$ & $\begin{array}{c}\text { Inside } \\
\text { diameter } \\
{[\mathrm{nm}]}\end{array}$ & $\begin{array}{c}\text { Specific } \\
\text { area } \\
{\left[\mathrm{m}^{2} / \mathrm{g}\right]}\end{array}$ & Density \\
\hline MWCNT & $>95$ & $10-50$ & $8-15$ & $3-5$ & 233 & 2.1 \\
\hline SWCNT & $>90$ & $5-30$ & $1-2$ & $0.8-1.6$ & 407 & 2.1 \\
\hline
\end{tabular}

Table 1

CHARACTERISTICS OF CARBON NANOTUBES

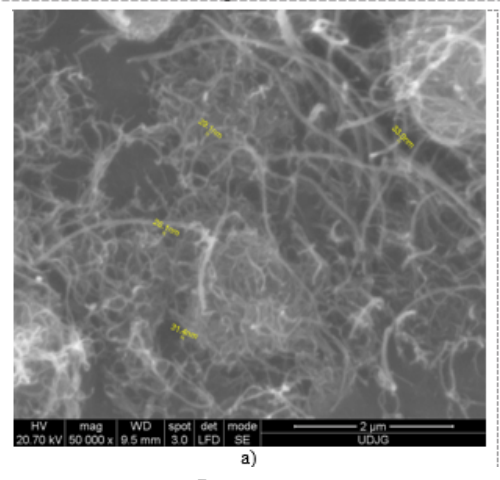

\section{Experimental part}

Materials and methods

Vinylester resin (VE) POLIMAL VE 11M used for the purpose of this research was purchased from SC Profesional SRL (Romania) and it was used as received, while carbon nanotubes (MWCNTs and SWCNTs with specific surface area of $233 \mathrm{~m}^{2} / \mathrm{g} 407 \mathrm{~m}^{2} / \mathrm{g}$ respectivly) were provided by Cheap Tubes Inc (USA) and were produced by combustion chemical vapor deposition (CCVD). The main characteristics of the investigated carbon nanotubes provided by the manufacturer, length, diameters and purity, are given in table 1 and typical micrographs of their structure are given in figure 1 . The ratio of nanotubes into vinylester resin was determined by the CNTs weight content of 0.1 wt.\%, 0.15 wt. $\%$ and 0.2 wt. $\%$.

Friction and wear tests were conducted using a pin-ondisc device on the universal tribometer UMT-2 (CETR ${ }^{\circledR}$, USA), according to ASTM G99 standard, at room temperature under dry sliding condition. Before test, the pin specimen ( $6.25 \mathrm{~mm}$ in diameter and $25 \mathrm{~mm}$ in length) and the counterpart disc, made from steel 42CrMo4 (EN 10083-3:2006) were cleaned with acetone. The mass loss of the pin was measured with an analytical balance (Mettler Toledo AB204-S/Fact, accuracy $0.01 \mathrm{mg}$ ) for the specific wear rate calculation. Sliding velocity was set to $0.5 \mathrm{~m} / \mathrm{s}, 1$ $\mathrm{m} / \mathrm{s}$ and $1.5 \mathrm{~m} / \mathrm{s}$, and normal load to $10 \mathrm{~N}, 15 \mathrm{~N}$ and $20 \mathrm{~N}$. The wear of the composites was determined by the total weight loss after $1600 \mathrm{~m}$ sliding distance. Five tests were performed for each condition, thus 5 average values from steady state were available to calculate the average friction coefficient and wear rate of every material.

\section{Results and discussions}

Coefficient of friction and specific wear rate

In order to determine the specific wear rate, eq. 1 from, ASTM G 99, was used:

$$
W_{S}=\frac{1}{F_{N} \theta \rho} \times \frac{\Delta m}{\Delta t}
$$

where: $W$ s- specific wear rate, $\left[\mathrm{mm}^{3} / \mathrm{N} \cdot \mathrm{m}\right] ; F_{\mathrm{N}}=$ applied normal force, $[\mathrm{N}] ; \vartheta=$ velocity, $[\mathrm{m} / \mathrm{s}] ; \rho=$ density, $[\mathrm{kg} /$ $\mathrm{mm}^{3}$ ]; $\Delta \mathrm{m}=$ mass loss, $[\mathrm{kg}] ; \Delta \mathrm{t}=$ time interval, [s] .

Figure 2a) shows the friction coefficient of SWCNT and MWCNT/vinylester nanocomposites as a function of sliding speed, resulted from tests performed at $20 \mathrm{~N}$ constant load. During the tests, the temperature of the sliding surface is increasing due to the sliding speed and, accordingly, the thermal conductivity of the nanocomposite has significant influence on the tribological properties. Also, improved thermal conductivity of nanocomposite, due to the effect of CNTs, leads to a decreased temperature of the contact surface. On the other hand, the friction intensity slightly oscillates under the influence of enhanced thermal conductivity and improved reinforcement of the nanocomposite surface. Moreover, the presence of MWCNT in the resulted debris has lubricating effect which produces the decrease in the friction coefficient. The lower values of the friction coefficient observed in case of nanocomposites with $0.1 w t \%, 0.15 w t \%$ and $0.2 w t \%$ MWCNT may be due to the higher amount of MWCNTs into the specimen which leads to improved lubricating effect (Fig. 2a, b). The friction coefficient recorded in case of SWCNT / vinylester composites decreases at first and increases later, and it also reaches the lowest value for $1 \mathrm{~m} / \mathrm{s}$; finally, the value of COF increases by 1.2 times than that of neat vinylester. On the other hand, the increase in the friction coefficient that occurs in case of nanocomposite with SWCNT in relation to the vinylester resin may be determined by the debris containing SW CNTS which may act as a third body during the sliding motion. This effect tends to diminish, as sliding speed increases, when the lubricantion effect of SWCNTs is higher.

Figures $2 \mathrm{c}$ and $\mathrm{d}$ show that the wear rate of the CNTS/ vinylester composites generally decreased with applied load accompanied by a simultaneous decrease in the friction coefficient. Increasing the applied load makes the sliding surfaces to be subjected to higher compressive and shear stress which generate additional heat. In view of the thermal stability of the vinylester resin, heat generation by friction and its accumulation at the sliding surface produce local melting and softening of the polymer, which results in poor strength of the vinylester matrix. Comparing the effect of two types of carbon nanotubes (SWCNTs and MWCNTs), it can be noticed that for the same percentage of CNTS, the values are slightly lower in the case of MWCNT. This difference is greater for higher percentages $(0.15 w t \%$ and $0.2 \mathrm{wt} \%)$. The result indicates that stronger interaction between vinylester resin and MWCNTs has a significant influence on the friction behavior, which is particularly noticeable at higher CNTs contents Fig. 3a, b). As it can be seen in Figures 3c) and d), the specific wear rate is smaller in case of composite with SWCNTs, according to the values of COF (Fig. 3a, b). During the sliding test, most of MWCNTs, exposed at the interface, have been spread into smaller debris and subsequently incorporated into the transfer film, upon the counterface, which may be responsible for the decreasing friction coefficient. Friction coefficient of MWCNT/ vinylester composites continuously increase with the sliding speed, but compared to pure vinylester resin, 


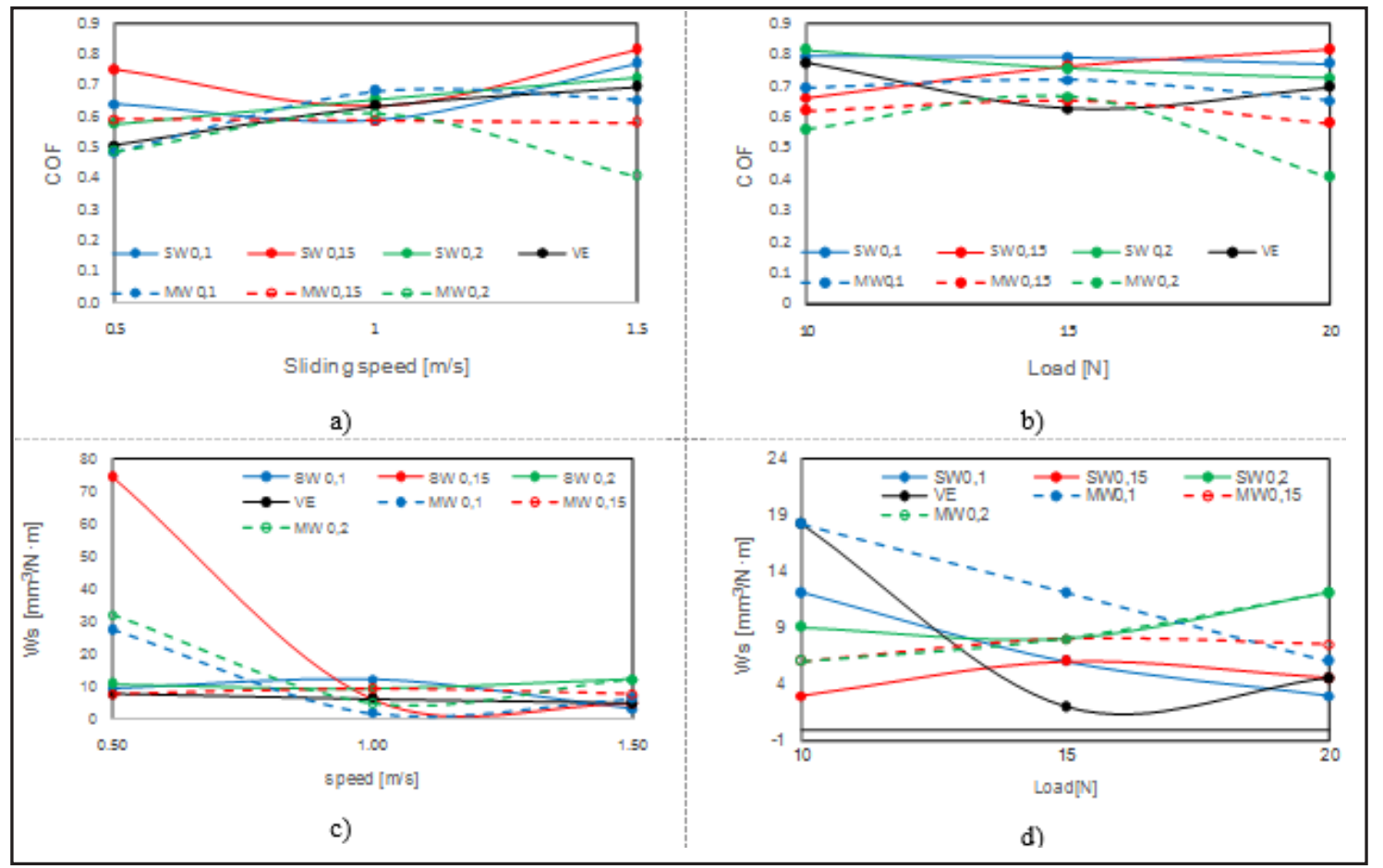

Fig. 2. a) COF vs. speed at normal load, 20N; b) COF vs. load at sliding speed, $1.5 \mathrm{~m} / \mathrm{s} ; \mathrm{c}$ ) Ws vs. content at normal load, $15 \mathrm{~N} ;$ d) Ws vs. content at sliding speed, $1.5 \mathrm{~m} / \mathrm{s}$

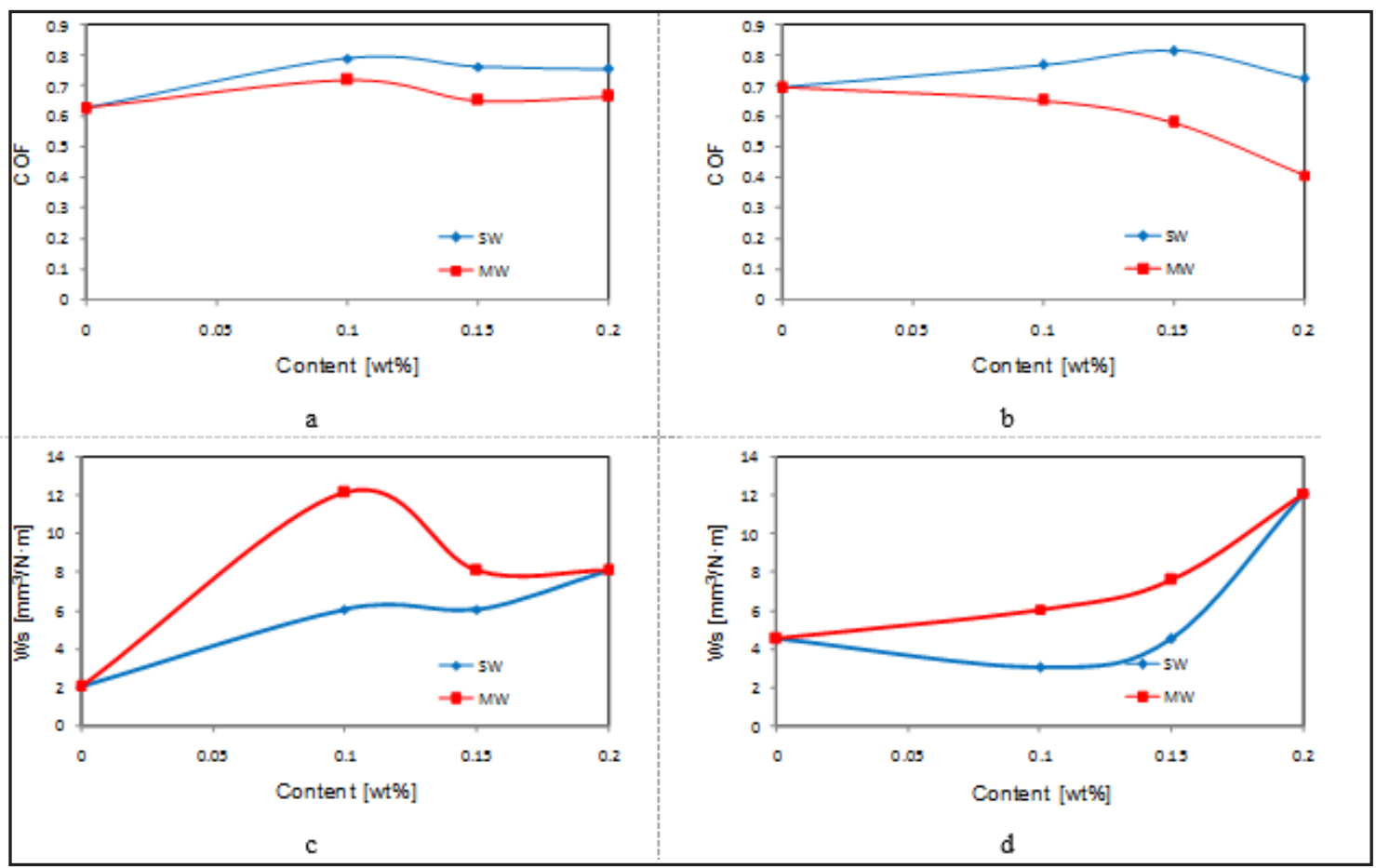

Fig. 3. a) COF vs. content at normal load, $15 \mathrm{~N}$, and sliding speed, $1.5 \mathrm{~m} / \mathrm{s}$; b) COF vs. content at normal load, $20 \mathrm{~N}$ and sliding speed, $1.5 \mathrm{~m} / \mathrm{s} ; \mathrm{c})$ Ws vs. content at normal load, 15N, and sliding speed, $1.5 \mathrm{~m} / \mathrm{s} ;$ d) Ws vs. content at normal load, $20 \mathrm{~N}$ and sliding speed, $1.5 \mathrm{~m} / \mathrm{s}$

MWCNT/ vinylester composites exhibit a lower value of friction coefficient under almost all test conditions. At the same time, SWCNT/ vinylester composites show a lower coefficient of friction compared to pure vinylester resin, at low sliding speed. Therefore, SWCNT/ vinylester composite exhibit both low wear resistance and high friction coefficient, compared to the pure vinylester resin. It was found that MWCNTs could reduce the friction and increase the specific wear rate of the vinylester composites, which results from the reinforcing and self-lubricating effect of MWCNTs over the polymer matrix.

\section{Friction stability}

Wear behavior and friction of polymer composites are influenced by material properties and test conditions. Industrial applications require not only low friction coefficient and specific wear rate, but a certain wear intensity and stability of motion. Thus, friction stability may be calculated according to Eq.2:

$$
F_{s}=\frac{\mu_{\operatorname{med}}}{\mu_{\max }} \times 100
$$

where: Fs is friction stability [\%], $\mu_{\mathrm{m}}$ is mean coefficient of friction from steady state region and $\mu_{\max }$ is the maximum coefficient of friction from steady state region. The friction 


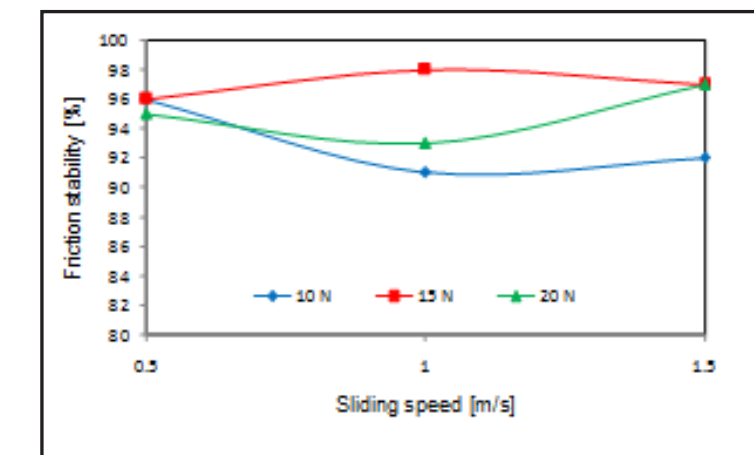

behavior of SWCNT and MWCNT/ vinylester nanocomposites was further studied in terms of friction stability against the sliding speed (Fig. 4). When the curves of friction stability are flat and do not show undulations, the stability range is higher. That means the composite proves minimum sensitivity towards normal load or sliding speed. If the curves exhibit sharp slope, the friction stability of materials is poor. The stability range of composites was as follows: SW 0.15 (91-98\%), VE (90-99\%), MW 0.15(89$99 \%)$, SW 0.2 (86-98\%), MW 0.1 (86-99\%), SW 0.1 (77$97 \%)$, MW 0.2 (84-95\%). The best friction stability has been noticed in case of the nanocomposite SW 0.15 . Its range of friction stability variation (91-98\%) was the lowest and the slope was minimal. This might be due to increase in coefficient of friction caused by the presence of SWCNT,

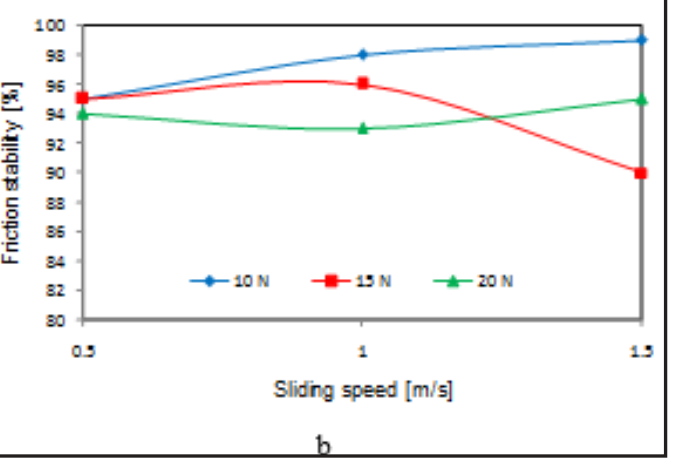

Fig. 4. Friction stability vs. sliding speed for:

a) SW 0.15 ; b) VE

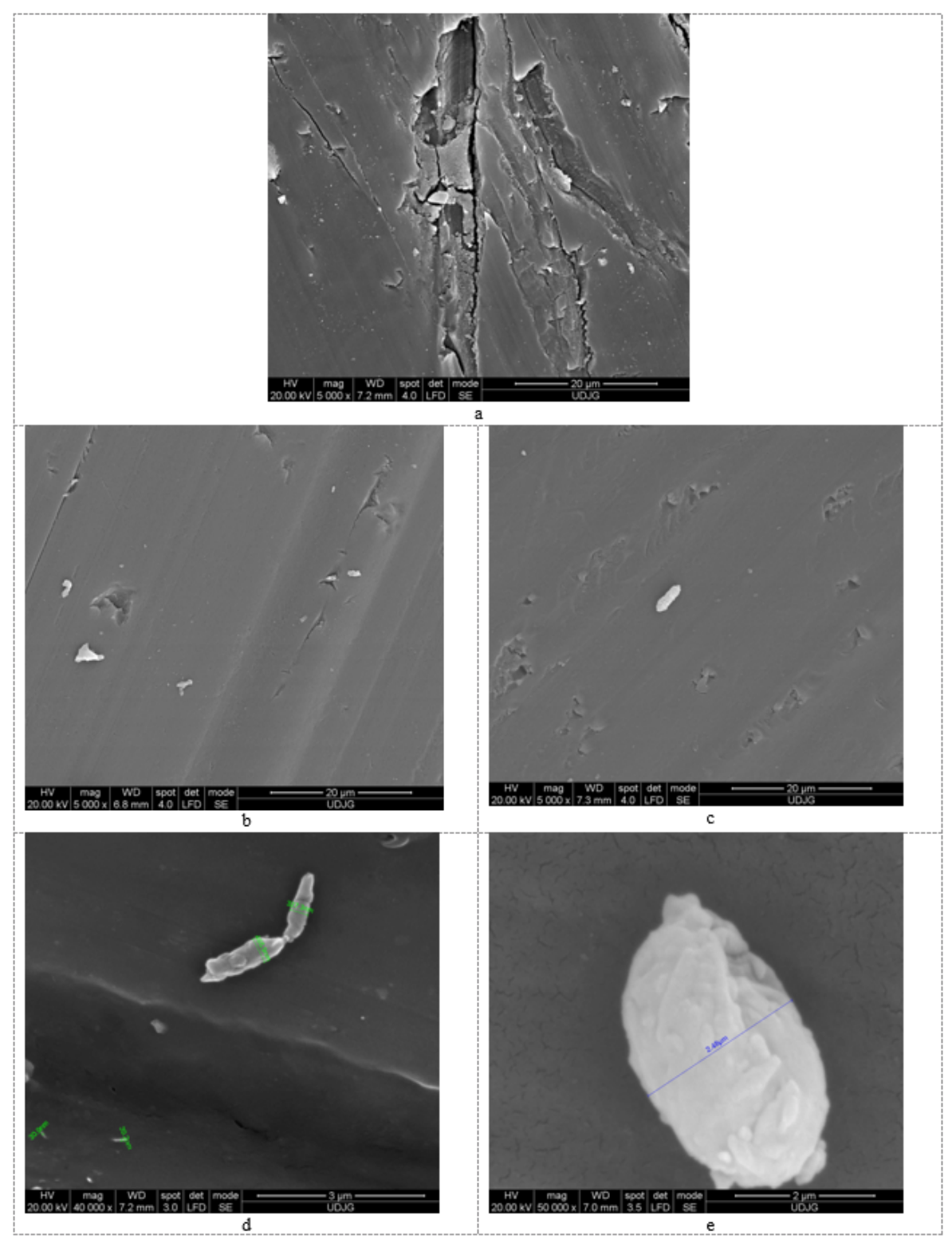

Fig. 5. SEM images of: a) neat vinylester ; b)MW 0.1 ; c) SW 0.15; d) MW 0.15; e) SW 0.2

accumulation of friction heat and occurrence of debris between contacting surfaces. Vinylester resin and MW 0.15 composite were next in performance, taking into account friction stability, and SW 0.1 and MW 0.2 showed poor friction stability. This variation in friction stability may be caused by the effect of the third body which contains a mixture of vinylester resin, carbon nanotubes, and steel particles, originated from the counterpart disk.

\section{SEM analysis}

SEM images of the worn surfaces of pure vinylester and its composites have been analyzed to investigate the effect of carbon nanotubes on the worn surface. As figure 5 shows, the tested surface is very rough, displaying traces which are specific for adhesive and abrasive wear. Such a 
worn surface is caused by the weak wear strength of the neat vinylester resin, in sliding motion against the steel disk. It can be seen that more obvious furrows occur on the worn surface of the vinylester specimen. By contrast, the abrasive and adhesion wear of the tested surface of MW 0.1 and SW 0.15 is considerably reduced (Fig. 5b, C). The relatively smooth, uniform, and compact worn surface is in good agreement with the considerably increase in wear strength of the vinylester/CNTs nanocomposites. After incorporating CNTs into the vinylester matrix, the SEM images reveal milder damage (see Fig. 5b, c). This result is consistent with the lower wear rate and mainly attributed to the effect of CNTs. Therefore, it can be deduced that the incorporation of CNTs contributes to diminish the wear intensity of the vinylester matrix in sliding against the steel counterface. Consequently, the vinylester/CNTs nanocomposites show a better wear strength than neat vinylester. Therefore, it can be reasonably assumed that tribological behaviour of the vinylester/CNTs nanocomposite is highly dependent on the adhesion between CNTs and vinylester matrix and a good dispersion of the CNTs.

\section{Conclusions}

In the present study, the friction and wear behaviour of SWCNT and MW CNT/vinylester nanocomposites has been investigated under dry sliding condition, during the pin-ondisc test. Based on the obtained results and qualitative analysis of SEM images, the following conclusions can be drawn:

-SWCNTS do not have a significantly influence on the friction behavior of vinylester resin, as compared to the improved friction behavior of MW CNT/vinylester resin. The lowest value of friction coefficient is 0.4 for MW 0.2 . This value of COF was by $42 \%$ lower than those of neat vinylester resin.

- Carbon nanotubes may improve significantly wear behavior of vinylester resin. The specific wear rate of MWCNT/vinylester nanocomposites decreased with increasing sliding velocity. The specific wear rate of MWCNT/vinylester nanocomposites was lower than those of neat vinylester resin, in almost all performed tests. The specific wear rate of MWCNT/vinylester nanocomposites was considerable lower than that of neat vinylester resin, under the test performed with $15 \mathrm{~N}$ load and speed of 0.5 $\mathrm{m} / \mathrm{s}$.

-The wear mechanism of CNTs/vinylester nanocomposites was slightly abrasive and adhesive wear. Some micronic and submicronic particles of polymer and steel, which generate wear debris, have been revealed by SEM.

-Friction stability showed the lower influence of sliding speed on the friction coefficientfor SW 0.15 . Neat vinylester resin revealed a better friction stability compared to the other composites. This implies that the heat exchange between contact surfaces was lower in case of nanocomposites, as compared to those given by vinylester resin.

Acknowledgement: The work has been funded by the Sectorial Operational Programme Human Resources Development 2007-2013 of the Ministry of European Funds through the Financial Agreement POSDRU/159/1.5/S/132397 ExcelDOC.

\section{References}

1. YAN, L., WANG, H., WANG, C., SUN, L., et al., Wear, 308, 2013, p. 105 2. CUI, L.-J ., GENG, H.-Z., WANG, W.-Y., CHEN, L.-T., GAO, J., Carbon, 54, 2013, p. 277
3. SANES, J., SAURIN, N., CARRION, F.J., OJADOS, G., BERMÚDEZ, M.D., Compos. Part B: Eng.,105, 2016, p. 149

4. ANDREI, G., DIMA, D., BIRSAN,I., ANDREI, L., CIRCIUMARU, A., Mat. Plast., 46, 2009, p. 284

5. CIRCIUMARU, A., ANDREI, G., BIRSAN,I., SEMENESCU, A., Mat. Plast., 46, 2009, p. 211

6. DIMA, D., ANDREI, G., Materialwiss. Werkst., 34, 2003, p. 349

7. SIDDHARTHA, KULDEEP, G., Mater. Des., 35, 2012, p. 467

8. WANG, H., CHANG, L., YANG, X., YUAN, L., et al., Carbon, 67, 2014, p. 38

9. BAHADUR, S., Wear, 245, 2000, p. 92

10. HUANG, J., RODRIGUE, D., Mater. Des., 55, 2014, p. 653

11. SHIVAMURTHY. B., BHAT, K.U., ANANDHAN, S., Mater. Des., 44, 2013, p. 136

12. SHEN, X.J., PEI, X.Q., LIU, Y., FU, S.Y., Compos. Part B: Eng., 57, 2014, p. 120

13. YANG, S.-Y., LIN, W.-N., HUANG, Y.-L., TIEN, H.-W., et al., Carbon., 49, 2011, p. 793

14. MIN, C., LIU, D., SHEN, C., ZHANG, Q., et al., Tribol. Int., 117, 2018, p. 217

15. ZHANG, L.C., ZARUDI, I., XIAO, K.Q., Wear, 261, 2006, p. 806

16. GANDHI, R.A., PALANIKUMAR, K., RAGUNATH, B.K., DAVIM, J.P., Mater. Des., 48, 2013, p. 52

17. DIKE, A.S., MINDIVAN, F., MINDIVAN, H., Int. J. Surf. Sci. Eng., 8, 2014, p. 292

18. VIJAYARAGHAVAN, V., GARG, A., WONG, C.H., TAI, K., MAHAPATRA, S.S., Measurement, 50, 2014, p. 50

19. LI, Y., WANG, Q., WANG, T., PAN, G., J. Mater. Sci., 47, 2012, p. 730 20. PARK, S., AN, J., PINER, R.D., JUNG, I., et al., Chem. Mater., 20, 2008, p. 6592

21. GOLCHIN, A., WIKNER, A., EMAMI, N., Tribol. Int., 95, 2016, p. 156 22.CAMPO, M., JIMÉNEZ-SUÁREZ, A., UREÑA, A., Wear, 324-325, 2015, p. 100

23. SAMAD, M.A., SINHA, S.K., Tribol. Int., 44, 2011, p. 1932

24. SAMAD, M.A., SINHA, S.K., Tribol. Lett., 38, 2010, p. 301

25. SONGFENG,E., SHI, L., GUO, Z., Appl. Surf. Sci., 292, 2014, p. 750 26. DIEZ-PASCUAL, A.M., NAFFAKH, M., GONZALEZ-DOMINGUEZ, J.M., ANSON, A., et al., Carbon, 48, 2010, p. 3500

27. CAO, Z., QIU, L., YANG, Y., CHEN, Y., LIU, X., J. Mater. Res., 29, 2014 , p. 2625

28. RYU, B.-H., BARTHEL, A.J., KIM, H.-J., LEE, H.-D., et al., Compos. Sci. Technol., 101, 2014, p. 102

29. LIU, H., WANG, T., WANG, Q., Polym., Plast. Technol. Eng., 51, 2012, p. 1

30. BAKSHI, S.R., TERCERO, J.E., AGARWAL, A., Compos. Part A: Appl.

Sci. Manuf., 38, 2007, p. 2493

31. MAKOWIEC, M.E., BLANCHET, T.A., Wear, 374-375, 2017, p. 77

32. LIU, C.-X., CHOI, J.-W., Nanomaterials, 2, 2012, p. 329

33. KALIN, M., ZALAZNIK, M., NOVAK, S., Wear, 332-333, 2015, p. 855 34. GUIGNIER, C., BUENO, M.A., CAMILLIERI, B., LE HUU, T., et al., Tribol. Int., 100, 2016, p. 104

35. GUIGNIER, C., BUENO, M.A., CAMILLIERI, B., TOURLONIAS, M., DURAND, B., Compos. Part A: Appl. Sci. Manuf., 71, 2015, p. 168 36. KHUN, N.W., TROCONIS, B.C.R., FRANKEL, G.S., Prog. Org. Coatings, 77, 2014, p. 72

37. LEE, S.M., SHIN, M.W., JANG, H., Wear, 320, 2014, p. 103

38. CHENG, H., CHENG, X., High Perform. Polym., 25, 2013, p. 611

39. KANDANUR, S.S., SCHRAMEYER, M.A., JUNG, K.F., MAKOWIEC, M.E., et al., Tribol. Trans., 57, 2014, p. 821

40. MOHAMMED, A.S., FAREED, M.I., Wear, 364-365, 2016, p. 154

41. DÍEZ-PASCUAL, A.M., NAFFAKH, M., Mater. Chem. Phys., 135, 2012, p. 348

42. MURARESCU, M., DIMA, D., ANDREI, L., CIRCIUMARU, A., Dig J Nanomater. Biostructures, 9, 2014, p. 653

43. CIUPAGEA, L., ANDREI, G., DIMA, D., MURARESCU, M., Dig J Nanomater. Biostructures, 8, 2013, p. 611

44. GOLCHIN, A., FRIEDRICH, K., NOLL, A., PRAKASH, B., Wear, 328329, 2015, p. 456

45. CARRION, F.J ., ESPEJ O, C., SANES, J., BERMUDEZ, M.D., Compos. Sci. Technol., 70, 2010, p. 2160

Manuscript received: 8.07 .2019 